\title{
Experiências estéticas na docência: o cinema como dispositivo formativo
}

\author{
Vanessa Alves da Silveira de Vasconcellos \\ Valeska Fortes de Oliveira \\ Universidade Federal de Santa Maria
}

\section{Resumo}

A potência formativa e as contribuições para a experiência estética docente que o cinema provoca nos tempos e espaços acadêmicos é evidente, seja na formação inicial, seja na formação continuada dos professores. Acreditamos que seria importante pensar, na formação docente, a educação do olhar. E o cinema, diante disso, pode provocar essa formação e implicar pessoas em experiências éticas e estéticas. Dessa forma, apresentamos uma experiência desenvolvida com professores da cidade de Santa Maria/RS, decorrente da pesquisa desenvolvida pelo Grupo de Estudos e Pesquisa em Educação e Imaginário Social - GEPEIS no projeto: “Em tempos de formação - o cinema, a vida e o cuidado de si: Exercícios autobiográficos e coletivos na atividade docente".

Palavras-chave: Formação. Cinema. Experiência estética. Dispositivo. 


\section{Aesthetic experiences in teaching: cinema as a formative device}

The formation power and contributions to the teaching aesthetic experience that cinema arouses in academic spaces and timing is evident, both in the early or continued education of teachers. We believe that it would be important to think on the teaching formation, about educating the views, the sensitivity, and cinema, regarding such matters, may provoke formation, and more specifically, may implicate people in aesthetic and ethical experiences. Thus, we present an experience developed with teachers from Santa Maria, RS, originated from the research developed by the Study and Research Group GEPEIS, with the Project: "Within times of formation - cinema, life and caring for oneself: Autobiographical and collective exercises in the teaching activity".

Keywords: Formation. Cinema. Aesthetic experience. Device.

\section{Experiencias estéticas en la enseñanza: el cine como dispositivo formativo}

El poder de la formación y sus contribuciones a la experiencia estética de la enseñanza que el cine provoca en el tiempo y en el espacio académico es evidente, sea en la formación inicial o en la continua. Creemos que sería importante pensar dentro de la formación docente, la formación de la mirada y el cine, frente a esto, puede desencadenar la formación e involucrar a la gente en las experiencias éticas y estéticas. De esta forma presentamos un estudio desarrollado con profesores de la ciudad de Santa Maria, RS, derivados de la investigación llevada a cabo por el Grupo de Estudio e Investigación GEPEIS con el proyecto: "En tiempos de la formación - el cine, la vida y el autocuidado: Ejercicios autobiográficos y colectivos en la actividad docente".

Palabras-clave: Formación, Cine, experiencia estética; dispositivo. 


\section{A formação estética e o cinema como dispositivo}

Uma vez li uma frase - com certeza de algum autor famoso que dizia algo assim como a vida está feita da mesma matéria dos sonhos. Eu digo que a vida pode perfeitamente estar feita da mesma matéria dos filmes. Contar um filme é contar um sonho. Contar a vida é como sonhar um sonho ou contar um filme. (Rivera, 2012, p.58)

As reflexões e pesquisas sobre formação de professores são estudos que adentram em um campo complexo, no sentido de perceber esta como algo singular, que diz respeito a diferentes trajetórias e processos formativos distintos. Isso tudo baseia-se, também, em um repertório de vivências pessoais, que, de certa forma, mobilizam conhecimentos, saberes diversos na atuação profissional docente.

Nesse viés, a formação de professores envolve processos inacabados, que implicam tempos e espaços da vida docente, em suas idas e vindas, e extrapolam qualquer currículo de curso ou espaço acadêmico, pois são complexos, singulares e se relacionam com as experiências vividas. A noção de formação que aqui se quer estabelecer está relacionada com o inacabamento e com a própria responsabilidade do docente para efetivar esse processo; ou seja, o sujeito se forma - é um processo pessoal -, buscando a percepção de seu desenvolvimento a partir de seus próprios movimentos de busca, mudanças e transformação.

A respeito disso, Ferry (2004, p.54) afirma: "Ninguém forma o outro", nesse sentido é que os indivíduos se formam por si mesmos por meio das mediações os suportes que permitem a possibilidade de formação, mas não são a formação propriamente dita. Cada um é responsável por sua formação, que é mediada por dispositivos como leituras, relações com os outros, grupos de pesquisas e de aprendizagem, cursos, entre outras atividades que mobilizam saberes, possibilitando um processo formativo e o desenvolvimento do docente.

Nesse diapasão, Souto (2007) acredita que o dispositivo sempre promove criação, mudanças, transformação, incrementando a teoria da qual provem, como "un espacio estratégico y táctico que es revelador de significados, analizador de situaciones, provocador de aprendizajes y nuevas formas de relación y organizador de transformaciones". (Santos, 2007, p.21)

Dessa forma, quando aqui falamos em dispositivo, remetemos-nos a esta perspectiva do conceito proposto por Souto $(1999,2007)$, que traz suas contribuições para a discussão deste termo, apresentando um histórico de como surgiu e quando esse conceito passou a possuir um significado relevante para a formação. Com a uniformidade que as práticas escolares adotavam, e ainda adotam, com um modelo único de educação, o termo dispositivo não possuía nenhum sentido.

A mudança de significado perante este conceito passou a ocorrer na formação 
de adultos, que, diante das novas demandas e necessidades, buscaram formas diferenciadas para responder a elas. Ao criar essas novas estratégias de trabalho, começou a se utilizar na formação a noção de implementação de dispositivos pedagógicos.

Como um provocador de formação, como provedor de condições que podem ou não acontecer, os dispositivos são meios para que ocorram o desenvolvimento e a formação, e, ao mesmo tempo, não são garantias de que esta ocorra. Assim:

Los dispositivos, los contenidos de aprendizaje, el currículum no son la formación em si, sino médios para la formación, podemos preguntarnos cuáles son las condiciones fundamentales para que esta dinâmica de desarrollo orientada hacia la adquisición de algunas formas se produzca. Es decir, cuáles son las condiciones requeridas para que la formación tenga lugar. (Ferry, 2004, p. 55)

Compartilhamos a ideia de que a própria pessoa que se forma é o principal ator de seu processo de formação, mediada pelos dispositivos que se dispõem e que são vivenciados por cada docente. Pimenta (2002) reafirma essa ideia, assumindo que esse processo é contínuo e que, na verdade, refere-se à autoformação, uma vez que os docentes reelaboram os saberes iniciais confrontando estes em sua prática e em suas experiências formativas, seja no contexto escolar - em palestras, reuniões pedagógicas, leituras, enfim, nos diferentes espaços e tempos do exercício da docência -, seja fora deste.

E a questão que se coloca aqui e também inspira este artigo é: o que gera esse confronto? 0 que faz o docente pensar, refletir a respeito das concepções, representações, vivências que traz consigo em relação à escola, aos alunos e à sua prática? 0 que faz este abrir-se a novos horizontes? Buscar perguntas e respostas sobre os novos e antigos dilemas a respeito da educação?

Aproveitando-nos do título da obra de Alain Bergala (2008), "A hipótese-cinema” como uma figura potente para pensar na concepção de dispositivo, lançamos a hipótese de que o cinema pode provocar formação e, mais especificamente, pode implicar as pessoas em experiências éticas e estéticas.

A “hipótese-cinema" pode constituir-se numa possibilidade para confrontar os saberes e as representações construídas, permitindo produzir novos sentidos, outros olhares e significações a respeito de questões sociais, de questões da produção da subjetividade no mundo contemporâneo, da própria ação como docente e da postura enquanto professor.

No texto intitulado "Os professores e o cinema na companhia de Bergala", Ramos e Teixeira (2010, p. 7) afirmam que "uma das principais contribuições de Bergala contidas na hipótese-cinema é a ideia de que essa arte na escola, como 
as demais, é um encontro com a alteridade." Com a possibilidade de ir além da concepção que didatiza o uso do cinema, do documentário, na escola, o exercício fílmico pode transpor, provocar o pensamento por outros territórios e experiências, interrogando o instituído.

Outra provocação da hipótese-cinema é a ideia de que o cinema deve estar na escola não como conteúdo curricular, de uso e domínio de alguns professores, mas, distanciando-se de uma lógica instrumental, pode provocar experimentações e aprendizados de diferentes ordens e, também, desordens.

Como apontam Ramos e Teixeira (2010, p. 8), “Trata-se, ao revés, de um encontro com o cinema como expressividade, como um largo horizonte de possibilidades que permitam a experiência estética, seja quem for o docente ou discente."

Este movimento provocado pelo dispositivo cinema refere-se à ideia de que os filmes podem possibilitar a experimentação dos sentidos. Podem movimentar nossos corpos biográficos (Josso, 2011) a deslocamentos, a desconstruções e vivências éticas e estéticas, permitindo sempre mais, na perspectiva de ampliação dos repertórios pessoais. É como arte que se pretende olhar o cinema dentro da escola, no sentido de percebê-lo como uma necessidade, porque auxilia na compreensão da realidade e na transformação desta, por meio da magia, do imaginário que o envolve.

Duarte (2002) defende que cada um tem sua forma de relacionar-se com o cinema, pois essa relação implica escolhas, gostos, avaliações e aprendizagens. Cada um desenvolve sua própria intuição na configuração do seu cinema pessoal, e essa sensibilidade se amplia ao seu próprio modo e tempo, numa esfera intuitiva, pessoal, subjetiva e intransferível.

Nesse sentido, percebemos a potência formativa e as contribuições para a experiência estética docente que o cinema provoca nos tempos e espaços acadêmicos, seja na formação inicial, seja na formação continuada dos professores. Assim como Fischer (2009), também acreditamos que seria importante pensar, na formação docente, a educação do olhar, da sensibilidade, da ética, em que o professor, imergindo-se em outras formas de linguagens, dialogando com os filmes, interagindo com os movimentos, sons, imagens, por meio do cinema, por exemplo, poderia possibilitar uma prática consigo mesmo. Uma experiência consigo na perspectiva de cuidado de si e de um tempo para si.

Formação assumida com uma escolha da própria existência, como busca de um estilo de vida, de um cuidado consigo, que de maneira alguma poderia ser identificado com o culto narcísico de nosso tempo. (Fischer, 2009, p. 95) 


\section{0 trajeto de um grupo de estudos e pesquisas e o encontro com 0 cinema}

Partindo dessas concepções e conceitos balizadores, apresentamos uma experiência desenvolvida com os professores do município da cidade de Santa Maria, Rio Grande do Sul, decorrente da pesquisa desenvolvida pelo Grupo de Estudos e Pesquisa em Educação e Imaginário Social - GEPEIS com o projeto: “Em tempos de formação - o cinema, a vida e o cuidado de si. Exercícios autobiográficos e coletivos na atividade docente".

O GEPEIS vem desenvolvendo pesquisas na área de formação de professores há 20 anos, alicerçado no campo teórico e metodológico do imaginário social de Cornelius Castoriadis. Nosso grupo é composto por bolsistas de iniciação científica da graduação, mestrandos, doutorandos, professores de escolas da rede municipal e estadual de ensino e professores de instituições de ensino universitário.

Durante esses anos, algumas temáticas foram sendo incorporadas ao imaginário social nas pesquisas do grupo, como as questões de gênero, de poder, da subjetividade, do cuidado de si, a memória docente, o corpo biográfico, dispositivos grupais, histórias de vida, e, por último, a provocação para pensar o cinema como um dispositivo - o cinema que, assim como o imaginário, procura propor outras perguntas e novos caminhos para antigos problemas da educação. Em relação aos aspectos teórico-metodológicos que norteiam as pesquisas desenvolvidas no GEPEIS, destacamos os estudos com as narrativas de vida, pautando-se no método (auto) biográfico.

A utilização da abordagem biográfica na área da educação evidencia as experiências educacionais dos sujeitos, potencializa entender os diferentes mecanismos e processos relativos à educação em seus diferentes tempos, assim como permite adentrar num campo subjetivo, por meio das narrativas dos professores sobre seus processos formativos, buscando entendê-los dentro de seu trajeto de vida.

É por meio das narrativas que esta abordagem toma corpo, toma forma, conferindo vida aos personagens da pesquisa, definindo valores, construindo fatos, ações, acontecimentos, relações com o meio, fazendo com que cada evento relatado encontre seu lugar e significação na história contada pelo sujeito.

Ao trabalharmos com as narrativas de indivíduos, é necessário levar em consideração que não temos acesso ao fatos em si, à vida de uma pessoa, mas às elaborações, às construções, às invenções, porque esta é a concepção epistemológica que assumimos. As narrativas elaboradas, por meio da fala e da escrita, são matérias transitórias, vivas, que se compõem e recompõem no momento em que são enunciadas. A narrativa de vida não se dá de uma vez por 
todas, ela se (re)significa a cada uma de suas enunciações e, ao mesmo tempo, reconstrói com ela o sentido da história que se enuncia.

Fazer o relato de algum momento da vida é trazer para o presente os sentidos das experiências vividas no passado, é encontrar o sentido de cada momento que entrelaça as relações sociais, pessoais e profissionais. E como afirma DeloryMomberger (2008, p.97): "0 que dá forma ao vivido e à experiência dos homens são as suas narrativas, como lugar no qual o indivíduo toma forma, no qual elabora e experimenta a história de sua vida".

Partindo desse referencial teórico metodológico, várias pesquisas foram desenvolvidas pelo GEPEIS, e foram firmadas muitas parcerias com escolas das redes municipais e estaduais, universidades, ONGs. Apoiados no tripé do ensino, pesquisa e extensão, o grupo não mediu esforços para aproximar universidadesociedade, buscando sempre uma relação de parceria com as instituições.

Nesse sentido, para ampliar nossos estudos sobre a temática do cinema, firmamos uma parceria com a Universidade Federal de Minas Gerais - UFMG, que também desenvolve pesquisas nessa área por meio do projeto "Enredos da vida, telas da docência: os professores e o cinema". Dessa forma, nossos estudos têm como problemática as relações, os enredos, os significados, as experiências e as práticas dos docentes com o cinema.

0 projeto objetiva pensar o que, nas vidas dos professores, nos interrogamos e buscamos compreender: algo mais acerca de seus encontros ou mesmo de seus desencontros com o cinema ontem e hoje, alinhados com os problemas da docência e da educação como um todo. Interrogamos e buscamos compreender suas ideias, seus sentimentos, suas experiências e práticas, seus trabalhos individuais e coletivos ligados ao cinema, dentro do seu ofício, contemplando suas memórias e histórias de vida.

0 pressuposto teórico-analítico desse trabalho parte de que os/as professores/ as são sujeitos socioculturais, que se diferenciam dos demais grupos, categorias e segmentos de trabalhadores a partir de sua condição de docentes. Em outras palavras, a condição docente demarca os processos de construção dos professores, particularizando-os em face de outros atores, segmentos e grupos sociais. Dessa forma se quis investigar com a pesquisa: como a arte do cinema se coloca nestes cenários e enredos da escola e da docência hoje? Por que falar e pensar o cinema na educação, na escola, na docência, no cotidiano da escola e nos processos educativos? 0 cinema integra as mídias contemporâneas, nas quais as novas gerações estão enredadas?

Assim, buscou-se identificar, caracterizar e analisar as relações e vivências de professores com o cinema. De um lado, no que se refere às suas histórias pessoais e profissionais e às formas pelas quais o cinema nelas se faz presente, 
buscando compreender as visões e concepções, os saberes e fazeres docentes acerca desta arte em suas vidas. De outro, interrogamos não somente a forma como o cinema se faz presente ou as razões de sua ausência no trabalho docente no cotidiano da escola, como também os significados e sentimentos inscritos em seus encontros com o cinema e suas práticas cinematográficas ou com o cinema dentro e fora da escola.

Após essa apresentação geral do projeto, na primeira etapa da pesquisa, foi realizado um levantamento de dados, junto aos professores e com a participação da Secretaria Municipal de Educação do município de Santa Maria, para analisar como o cinema está colocado nas histórias e vida dos professores coautores do projeto. Esta dimensão contemplou não somente como os docentes compreendem, definem e interpretam seus trabalhos educativo-pedagógicos com o cinema, mas também a presença ou possível ausência do cinema na vida pessoal dos professores, visto que ambas as dimensões, pessoais e profissionais não podem ser separadas.

Diante disso, aos professores que se mostraram favoráveis à participação da formação continuada, segunda etapa do projeto, foi enviado um convite para integrarem o GEPEIS, para que fossem compreendidos os sentidos e os significados que os professores atribuem ao cinema em suas vidas e histórias pessoais, como eles se relacionam com a arte cinematográfica. Foram exaltadas suas experiências, preferências, sentimentos, formação/conhecimentos relativos ao cinema por meio desse processo de formação continuada, construída com os professores participantes.

No terreno da formação de professores, é possível visualizar essa perspectiva de não apenas associar a formação ao progresso e ao desenvolvimento numa óptica futura, mas sim de ser considerada a possibilidade de retrospectiva, na qual o indivíduo constrói sua própria formação com base no balanço que este faz de sua vida. Autores como o próprio Nóvoa $(1995,2010)$, Josso $(2004)$, Dominicé (2010), Pineau (2010), Delory-Momberger (2008) têm chamado a atenção para uma teoria de formação dos adultos, pensando nesta como um trabalho de reflexão sobre os percursos de vida, colocando em evidência os saberes subjetivos e não formalizados que os indivíduos utilizam em suas experiências, nas relações sociais e profissionais.

Esses saberes, segundo Delory-Momberger (2008), são determinantes na maneira com que os sujeitos investem nos espaços de aprendizagens, e o seu reconhecimento permite que sejam realizadas novas relações com o saber e a formação. Dessa forma, “a valorização da experiência individual inscreve-se num procedimento global que associa, intimamente, os formados ao processo formativo e os considera como atores plenos de sua própria formação". (Delory- 
Momberger, 2008, p.95)

É dessa maneira que podemos visualizar o método biográfico, potencializando processos formativos, como uma alternativa para se produzir outro tipo de conhecimento sobre o professor e sobre suas práticas docentes. Dessa forma, ele deve ser entendido como uma perspectiva para a investigação educacional, que aparece como uma tentativa de encontrar uma estratégia que permita que o indivíduo torne-se sujeito-ator de seu processo de formação, por meio da apropriação de sua trajetória.

\section{Uma aproximação do perfil dos professores na "hipótese cinema"}

Numa análise dos questionários respondidos pelos professores de escolas públicas de Santa Maria, primeiramente buscamos conhecer o perfil dos professores, para saber quem são esses sujeitos. A segunda parte dos questionários foi composta por várias perguntas, que buscavam abarcar significações dos professores sobre o cinema. Dessa forma foram analisadas tais perguntas: Você costuma assistir a filmes? Com que frequência você assiste a filmes? Onde costuma assistir a filmes? Com quem você costuma assistir a filmes? Você utiliza filmes em seu trabalho como professor? Por quê? Você faria uma formação relacionada ao cinema? A partir dessas perguntas (fechadas e abertas), fizemos as primeiras relações e o convite para os encontros configurados no dispositivo cinema.

Por meio dos questionários, propusemos-nos relatar o panorama da relação dos professores com o cinema e, fazendo um levantamento geral, pudemos observar que foram respondidos 645 questionários dos 1.500 enviados às escolas. Percebemos que a maioria são professoras entre 31 e 40 anos, casadas, que possuem regime de trabalho de 40 horas, não possuem outra atuação profissional, gostam de ler, viajar, passear, acessar a internet, assistir à televisão e assistir a filmes nas horas livres. Esse foi o perfil dos professores das escolas municipais de Santa Maria que responderam os questionários; e, a partir deste contorno, tivemos a oportunidade de, nessa primeira parte da pesquisa, ter ideia do público envolvido, bem como saber o que eles gostam de fazer nas horas vagas.

É importante trazer uma discussão aqui referente ao tempo - e Castoriadis (1922) traz uma elucidação a respeito dessa questão, a qual é importante abordar, já que o tempo é pertencente a todo sujeito. 0 indivíduo está imerso em um tempo instituído pela sociedade e, conhecendo esse tempo, este deve acomodar-se aos acontecimentos pertencentes ao seu tempo privado e tempo público.

Castoriadis (1922) afirma que a sociedade se institui ao longo de duas dimensões do tempo, as quais são tecidas juntamente: uma conjuntista-identitária e outra 
propriamente imaginária. Para melhor compreensão, o autor define o tempo em conídico (identitário), aquele tempo do calendário, que pode ser medido e que se caracteriza pela repetição, recorrência e equivalência. Já o tempo imaginário é aquele dotado de significação e se compõe de representações, afetos e impulsos socialmente instituídos.

Fazendo uma relação dessa discussão teórica sobre o tempo, e ressaltando o que foi considerado no questionário a respeito do tempo livre dos docentes e o que estes faziam com essa disponibilidade, queremos aqui destacar a relação desse "tempo livre" com a relação do significado que as atividades desenvolvidas nesse período tinham para sua formação enquanto docente, enquanto indivíduo. Queremos compreender esse tempo dos professores, dentro de sua dimensão significativa, diante do que é realizado e que realmente afeta, atravessa suas concepções, suas representações, como um tempo que vai além do que pode ser medido, mas do que pode ser sentido diante de suas experiências.

A segunda parte dos questionários buscou compreender como o professor percebe essa relação do cinema com a sua vida e se essa linguagem realmente faz parte de suas vivências e profissão. Ao perguntarmos se costumam assistir a filmes, $85 \%$ respondeu que sim, $14 \%$ não costumam e 1\% não respondeu. Também nos interessou saber a frequência com que esses professores assistem a filmes: então, obtivemos $36 \%$ das respostas afirmando que assistem 2 vezes por semana ou mais, $27 \%$ costuma assistir a filmes 1 vez por semana, $19 \%$ assiste raramente, o que significa menos que uma vez por mês, $10 \%$ assistem 2 vezes por mês e $8 \%$ assistem uma vez por mês.

Foi possível observar que os professores costumam assistir a filmes em sua grande maioria e o fazem com frequência. Este é um resultado que nos motiva a continuar a pesquisa, pois não teria sentido dar seguimento se os professores não possuíssem alguma relação com o cinema, no sentido de percebê-lo como uma linguagem presente em suas vidas.

Consideramos relevante saber o local e com quem os professores assistem aos filmes, para inferir se o meio pessoal ou profissional prevaleceria. Visualizamos que quase a totalidade dos professores assiste em casa, o que representa $94 \%$, mas também assistem em cinemas e no trabalho, que juntos representam $6 \%$. A maioria dos professores assiste em companhia dos familiares, o que significa $56 \%$, seguido dos amigos e colegas de trabalho, somando juntos $13 \%$, mas também os que assistem sozinhos representam uma porcentagem significativa de $31 \%$. Constatamos que os professores assistem a filmes tanto em casa como no trabalho, na vida pessoal e profissional.

Chama-nos a atenção que os professores não costumam assistir a filmes em cineclubes, justamente um local que exibe gratuitamente filmes não comerciais, 
que buscam produzir um pensamento crítico, possibilitado pelo filme e pela riqueza do debate que há em torno da temática desenvolvida, diferente daqueles com intuito comercial. Assim, ficamos intrigados com a causa de os professores não frequentarem cineclubes, quando nossa cidade possui várias opções e iniciativas organizadas por várias instituições. Podemos dizer que é uma cidade com várias experiências de cineclubismo e, ainda, de festivais de cinema, realizados há bastante tempo como atividade cultural.

Em âmbito profissional, perguntamos se os professores utilizavam os filmes em seu trabalho: $91 \%$ disseram que sim, $5 \%$ não utilizam e $4 \%$ não responderam esta pergunta. Na sequência, foi levantado que, desses $91 \%$ que utilizam filmes em sala de aula, $57 \%$ utilizam como um recurso didático, $28 \%$ não especificaram, $8 \%$ utilizam por concebê-lo como uma forma de lazer e $7 \%$ não especificaram. Dessa forma, percebemos que, mesmo o cinema estando presente na vida e na profissão do professor, o filme é visto apenas como um recurso didático que ilustra conteúdos, como um apoio às aulas, sem utilizar todo o potencial cultural e formativo para o ser humano.

Para dar ênfase aos resultados, selecionamos algumas formas de como o professor utiliza os filmes em seu local de trabalho, e as repostas foram as seguintes: "integrando-o ao que está sendo trabalhado", "quase sempre com o tema estudado em aula”, “adequando-o ao conteúdo e nível dos alunos”, "de acordo com o tema de estudo, o filme é um ótimo recurso", "utilizo o filme para enfatizar o conhecimento sobre algum assunto", "de uma maneira que eu possa ilustrar meu trabalho, para que o assunto ensinado seja melhor assimilado". Percebe-se, então, que todas as respostas têm em comum o filme visto como um recurso didático. A didatização do cinema na escola é uma prática instituída na cultura docente e, ainda, tem sido utilizada como uma espécie de "professor substituto" àquele que não compareceu às suas aulas.

Após o levantamento destes dados, convidamos todos os professores a participarem da formação. Como já foi dito, somente 24 professores aceitaram o convite. Os encontros aconteceram aos sábados, pela manhã, no decorrer do segundo semestre do ano de 2012. Estes aconteceram intercalando atividades à distância com presenciais, utilizando textos, curtas-metragens, filmes e outros dispositivos para refletirmos as temáticas.

Nos encontros presenciais eram propostos, inicialmente, exercícios corporais. No primeiro encontro, realizamos uma dinâmica de apresentação, em que, conversando em duplas, os participantes teriam de buscar algumas informações para apresentar seu colega aos demais integrantes da roda. Esse foi o primeiro momento de interação que propusemos, o contato inicial com colegas de outras escolas, que foi avaliado como muito significativo, pois ouvir o outro, saber quem 
é, o que faz, onde trabalha, do que gosta é um importante exercício de cuidar do outro.

Em seguida, em um dos encontros, projetou-se o curta-metragem "0 guarani”. 0 curta é uma produção cinematográfica que propõe uma reflexão no que se refere à relação da população com o cinema, fazendo-nos pensar nas diferenças e semelhanças da relação cinema-pessoa(s), pensando a implantação do primeiro cinema no Brasil. A discussão que se seguiu ao curta foi muito significativa. Foram destacados alguns elementos importantes para o debate, como a desvalorização do cinema brasileiro em detrimento do estrangeiro e o entendimento de que os filmes servem apenas como dispositivos para a diversão, pois há uma redução do cinema a um programa de fim de semana, em que o que se prioriza em muitos casos é a ida ao shopping para fazer compras, lanches e, como mais uma opção de divertimento, a ida ao cinema.

Neste sentido, é possível pensar o cinema como algo maior do que a simples projeção, como provocador de questionamentos, dispositivo para pensar a nossa vida, inserida em uma cultura, como nos aponta Almeida (2001):

Momento estético em que um objeto artística e tecnicamente produzido vai ao encontro do imaginário do espectador, relacionar-se intimamente com seus desejos, ressentimentos, vontades, ilusões, raivas, prazeres, traumas, vivências, e sobre 0 qual só teremos nossa objetividade restituída após o término da projeção. Só então discutimos e falamos sobre ele, como memória, inextricavelmente ligado à nossa história, à história do mundo em que vivemos, à história do cinema. (Almeida, 2001, p.41)

É por essa via que entendemos o cinema: como objeto estético para pensarmos o mundo da cultura, que também nos permite a reconstrução de memórias, de falar e escrever sobre nossa vida, nossa história, associada ao contexto em que estamos. Consideramos que a experiência estética na formação do docente possibilita outro olhar aos sentidos, que perpassam os sujeitos e que necessitam ser (re)visitados. Pesquisar esses processos de significação se configura um caminho repleto de possibilidades, que conferem à formação um lugar propositivo, não apenas estático. Possibilita olhar o professor como alguém que percebe sua subjetividade.

Nestes encontros, algumas questões importantes já foram percebidas, como a presença de professores que realmente gostam de cinema e que estão se envolvendo nesse processo. Isso ressalta a ideia de que escolhemos temas que atravessam nossas vidas. Esta configuração produz a diferença na participação durante as atividades, a presença nos encontros e a qualidade das discussões. 
Observamos, com a aplicação dos questionários, a forte incidência do uso de filmes na escola, mas como um recurso didático, reduzindo seu valor e importância de patrimônio artístico e cultural da humanidade. No Brasil, o cinema dificilmente é visto na escola como fonte de conhecimento. Na maioria vezes, é considerado um recurso de lazer e entretenimento. É necessário ir além desse caráter ilustrativo, como pretexto para o desenvolvimento de certas atividades, e considerar a riqueza potencial e formativa do cinema como objeto de experiência estética, possibilitando a articulação entre cinema e arte/linguagem/expressão.

$\mathrm{Na}$ tentativa de compreender como o professor produz sentido aos processos formativos, Hermann (2010) fala que a experiência estética dá sentido à formação, pois se relaciona com a nossa capacidade de compreender a realidade pelo viés sensível, incitando movimentos de criação. Hermann (2010, p. 34) aponta para o perigo de uma educação reducionista, em que, "perdida a sensibilidade, a imaginação e os recursos de uma rica criação de si, a formação ética se desfigurou. De forma caricatural, se materializa nos currículos com um código".

As práticas formadoras, as pesquisas e os projetos que se preocupam em mobilizar dispositivos capazes de provocar a formação docente têm no cinema um aliado potente, capaz de afetar e produzir implicações por esta linguagem.

E pelo caminho da sensibilidade se pretende pensar essa formação que se deixando deslocar, desassossegar, interrogar, desaprender, refletir e aprender vai permitindo que a docência seja questionada pelo cinema, conduzindo esta por reflexões que revelam possibilidades e limites do docente em suas experiências singulares e plurais, enquanto sujeitos socioculturais.

0 cinema de cada um é feito de fragmentos articulados afetivamente, isto é, seguindo pressupostos do afeto. A palavra afeto vem do latim affectus, que significa tocar, atingir, alterar. 0 cinema afeta cada um de nós de forma diferente e altera nossa sensibilidade tanto quanto nossa racionalidade. (Duarte, 2012, p.5)

É necessário que sejamos afetados, que eduquemos e reeduquemos nosso olhar, que aprendamos e desaprendamos, que abandonemos antigas percepções e significações e que possamos ampliar, interrogar, abrir novos horizontes por meio das mais diferentes imagens, sons, linguagens que o cinema pode proporcionar. É necessário que os professores que estão se formando, ou aqueles que já trabalham nas escolas, conheçam outros territórios, paisagens, imagens capazes de ampliar repertórios, para além do que eles conhecem e do que é imposto cotidianamente pela mídia de consumo rápido e líquido. (Bauman, 2010)

Assim como Teixeira (2011), também acreditamos que o cinema deve: 
Estar nessa formação não como um conteúdo curricular e campo de especialidade de um professor, mas numa outra perspectiva, fugindo à racionalidade instrumental e às obrigações estritamente formais dos currículos, aprendizados e conteúdos a serem aferidos e mensurados pelos profissionais especializados nisto e naquilo. Trata-se, ao revés, de um encontro com o cinema como expressividade, como um largo horizonte de possíveis que permita a experiência estética, seja quem for o docente ou discente. $\mathrm{E}$ deve ser algo da ordem do desejo, algo esperado, significativo para os licenciados, para os futuros pedagogos, para os professores formadores que se disponham a arriscar com as novas gerações docentes outras pedagogias e viveres, outros fazeres e saberes, que envolvam as emoções, a inventividade, o prazer. (Teixeira, 2011, p.185)

É necessário que possamos ver o cinema como arte, como criação, que permite a interrogação e reflexão dos nossos modos de viver, nossos modos de agir, de pensar, de ver o mundo: outros olhos, o alargamento dos olhos, convidando-nos ao deslocamento, abrindo novos horizontes de compreensão e perspectivas do homem, do mundo, da escola e da docência.

\section{Considerações finais}

0 projeto que estamos desenvolvendo em coautoria com professores da rede municipal da cidade de Santa Maria tem produzido muitas aprendizagens acerca do potencial deste dispositivo - o cinema - na formação, seja ela inicial, seja ela continuada. Tirá-los dos seus cotidianos - fisicamente - e transportá-los para outros territórios, outras atmosferas com sons e cores, ativando a imaginação criadora, tem potencializado colocar o professor frente à pessoa que é ou, melhor, que pode se tornar. Observando-se nas projeções, percebe-se com tamanha dificuldade de estar frente a um dispositivo como o filme ou documentário, apenas para desfrutá-lo, apenas para uma experimentação de si. Percebemos, durante o curso realizado, que somente no último módulo, quando o foco era o cinema na escola e na sala de aula, os professores tomavam consciência da dificuldade de pensar ou experimentar o cinema como um cuidado de si.

Posto isto, reafirmamos a hipótese cinema como uma experiência ética e estética, provocadora para pensarmos a vida como obra de arte, na perspectiva da produção da existência.

Ainda cabe pontuar os desdobramentos destes encontros potentes em que a disposição de permanecer, de continuar, materializou-se nos trabalhos de produção e exercícios fílmicos em algumas escolas com os estudantes dos professores da rede, envolvidos no projeto. Da nossa parte, juntamos nossas 
energias e desejos de exercícios fílmicos autobiográficos que trazem à cena docentes que vêm realizando experiências significativas nas escolas, e, muitas vezes, sem visibilidade.

\section{Referências}

ALMEIDA, Milton José. Imagens e sons: a nova cultura oral. São Paulo: Cortez, 2001.

BAUMAN, Zygmunt. Capitalismo parasitário. Rio de Janeiro: Jorge Zahar, 2010.

BERGALA, Alain. A hipótese-cinema: pequeno tratado de transmissão do cinema dentro e fora da escola. Rio de Janeiro: Booklink; CINEAD-LISE-FE/UFRJ, 2008.

CASTORIADIS, Castoriadis. As encruzilhadas do labirinto III: o mundo fragmentado. Rio de Janeiro: Paz e Terra, 1922.

DELORY-MOMBERGER, Christine. Biografia e educação: figuras do indivíduoprojeto. Natal: EDUFRN; São Paulo: Paulus, 2008.

DOMINICÉ, Pierre. O processo de formação e alguns dos seus componentes relacionais. In: NÓVOA, A.; FINGER, M. (org.). 0 método (autolbiográfico e a formação. Natal: EDUFRN; São Paulo: Paulus, 2010. P. 81 a 95

DUARTE, Rosália. Cinema \& educação. Belo Horizonte: Autêntica, 2002.

DUARTE, Rosália. 0 cinema de cada um. Aula inaugural do projeto cineclube nas escolas da SME/RJ. Março, 2012.

FERRY, Gilles. Pedagogia de la formación. Buenos Aires: Centro de Publicaciones Educativas y Material Didáctico, 2004.

FISCHER, Rosa Maria Bueno. Docência, cinema e televisão: questões sobre formação ética e estética. Revista Brasileira de Educação, Rio de Janeiro, $\mathrm{n}^{\circ} .40$, jan.- abr. 2009.

HERMANN, Nadja. Autocriação e horizonte comum: ensaios sobre a educação éticoestética. Ijuí: Ed. Unijuí, 2010.

JOSSO, Marie Christine. Experiências de vida e formação. São Paulo: Cortez, 2004.

LETELIER, Hermán Rivera. A contadora de filmes. São Paulo: Cosak Naify, 2012. MARQUES, Claudio e HUGHES, Marília. O Guarani. [Filme-Vídeo]. Produção de Claudio Marques, direção de Claudio Marques e Marília Hughes. Bahia, 2008. 1 documentário, 20 min.

NÓVOA, Antonio. A formação tem que passar por aqui: as histórias de vida no Projeto Prosalus. In: NÓVOA, Antonio; FINGER, Mathias. (Org.). 0 método (auto) biográfico e a formação. Natal: EDUFRN; São Paulo: Paulus, 2010. p. 155 a 187.

NÓVOA, Antonio (Org.) Vidas de professores. Portugal: Porto, 1995.

PIMENTA, Selma Garrido (Org.). Saberes pedagógicos e atividade docente. São 
Paulo: Cortez, 2002.

PINEAU, Gaston. A autoformação no decurso da vida: entre a hetero e a ecoformação. In: NÓVOA, Antonio.; FINGER, Mathias (Orgs.). 0 método (auto) biográfico e a formação. Natal: EDUFRN; São Paulo: Paulus, 2010. p. 97 a 118.

RAMOS, Ana Lúcia Azevedo e TEIXEIRA, Inês Assunção de Castro. Os professores e o cinema na companhia de Bergala. Revista Contemporânea de Educação, Rio de Janeiro, v. 5, n. 10, jul -dez. 2010.

SOUTO, Marta. Repensando la formación: cuestionamentos y elaboraciones. 2007. (texto digitado - Aceptado para publicar em la Revista N. 1 de Educación de Palermol.

SOUTO, Marta. et. al. Grupos y Dispositivos de Formacion. Buenos Aires: Universidad de Buenos Aires/ Faculdad de Filosofia y Letras: Ediciones Novedades Educativas, 1999.

TEIXEIRA, Inês Assunção de Castro. Deslocando a câmera, imaginando cenas, criando roteiros: o cinema na formação de professores. In: FREITAS, Maria Teresa de Assunção (org.). Escola, Tecnologias Digitais e Cinema. Juiz de Fora: Editora UFJF, 2011. p. 169 a 192.

Recebido em outubro de 2013

Aprovado em novembro de 2013

Vanessa Alves da Silveira de Vasconcellos é mestre em Educação pela Universidade Federal de Santa Maria (UFSM), professora de rede municipal de ensino de Santa Maria e também atua no Curso de Pedagogia a distância na UFSM. E-mail: nessavasconcellosdamail.com

Valeska Fortes de Oliveira é doutora em Educação e professora titular da Universidade Fedral de Santa Maria, e pós-doutora em Ciências da Educação pela Universidade de Buenos Aires. E-mail: guizaAterra.com.br 